\title{
Survival and development of embryos of Gallus gallus domesticus treated with inorganic bromide
}

\author{
H.L. Lucht ${ }^{1}$, N.H. Casey ${ }^{1 \#}$ \& E. Sawosz ${ }^{2}$ \\ ${ }^{1}$ Department of Animal and Wildlife Sciences, University of Pretoria, South Africa \\ ${ }^{2}$ Department of Animal Nutrition and Biotechnology, Warsaw University of Life Sciences (SGGW), Poland
}

(Received 7 December 2017; Accepted 20 June 2018; First published online 5 July 2018)

\begin{abstract}
The range of bromide $\left(\mathrm{Br}^{-}\right)$in groundwater sources surveyed in South Africa is $0-18.4 \mathrm{mg} / \mathrm{L}$. The research aimed to establish chicken embryo sensitivity to a range of $\mathrm{Br}^{-}$treatments $(\mathrm{mg} / \mathrm{L}$ ) injected into fertilised Ross-308 eggs in three phases: (1) five eggs injected with $10 \mathrm{mg} \mathrm{Br} / \mathrm{L}$; (2) 45 eggs divided into groups and injected with 0,1 and $5 \mathrm{mg} \mathrm{Br} / \mathrm{L} ;$ (3) 148 eggs divided into groups injected with 0, 0.01, 0.05, 0.5 , and $1 \mathrm{mg} \mathrm{Br} / \mathrm{L}$. Incubation was at standard conditions. Breakout analysis was done at various stages of incubation. The mass of the embryo and of the heart, liver and brain was measured at Day 20. Statistical analysis used Statistical Analyses System ${ }^{\circledR}$ software FREQ procedure to determine the chi-square goodness-of-fit test for percentages of live or dead embryos within and between treatments. The GLM procedure was applied to test for differences in relative organ mass $(\mathrm{g})$ between treatments using F-test. The results showed: (1) $10 \mathrm{mg} \mathrm{Br}^{-} / \mathrm{L}$ is toxic; (2) $\mathrm{Br}^{-}$is lethal to embryos at concentrations $>1 \mathrm{mg} / \mathrm{L}$ and toxic at 1 $\mathrm{mg} / \mathrm{L}$; and (3) embryo survival was significantly negatively correlated $\left(R^{2}=-0.92\right)$ with increasing $\mathrm{Br}^{-}$ concentrations. Concentrations $>0.5 \mathrm{mg} \mathrm{Br} / \mathrm{L}$ showed greater risk on differential development. Concentrations $>0.01 \mathrm{mg} \mathrm{Br}^{-} / \mathrm{L}$ showed potentially severe effects on developing embryos. The heart showed the greatest relative growth response followed by the brain. The no observed adverse effect level target water quality range (NOAEL-TWQR) in developing chicken embryos was 0 - $0.01 \mathrm{mg} / \mathrm{L}$.
\end{abstract}

Keywords: Bromine, embryo model, halogens, maximum residue level, toxicity, water quality

\# Corresponding author: norman.casey@up.ac.za

\section{Introduction}

Inorganic bromide $(\mathrm{Br})$ occurs naturally as a water quality constituent (WQC) in groundwater sources across South Africa with concentrations ranging up to 18.4 mg/L (Casey \& Meyer, 2001; 2006; Meyer, 2015; Casey, 2016). The inorganic WQC in water sources have distinct influences on the quality of water according to their absolute and relative concentrations for the specific purpose of use and whether the exposure to the WQC is acute or chronic.

Water quality guidelines (WQG) are intended to assist user groups to gauge the suitability of the water according to the chemical constituents and physical properties. The WQG for inorganic WQC designate concentrations in generic terms as no observed adverse effect levels (NOAEL), constituents of concern (COC) where concentrations are approaching the WQG-values, and potentially hazardous chemical constituents (PHCC) where the WQC concentration exceeds the WQG-values. These designations assume chronic exposure. The WHO (2011) Guidelines for Drinking Water notes, however, that not all water sources will contain WQC with WQG-values and that WQC without WQG-values, or that are not addressed in the WQG, may be of legitimate local concern. Inorganic WQC occurring naturally in groundwater are due to geological characteristics (Meyer et al., 2000). These might include the chemical nature of the rock and soil deposits; historic sediments in aquifers; current geothermal, surface agricultural and mining activities; and migration of water between aquifers. As a result, the concentrations of WQC in groundwater are largely sitespecific. 
The current South African Water Quality Guideline for livestock watering does not list $\mathrm{Br}^{-}$as either a COC or a PHCC (Casey \& Meyer, 1996). The report by Casey and Meyer (2001) lists $\mathrm{Br}^{-}$as having a Target Water Quality Range (TWQR) of $0-3 \mathrm{mg} / \mathrm{L}$. A subsequent report (Casey \& Meyer, 2006) introduced 0.01 $\mathrm{mg} / \mathrm{L}$ as a WQG value to align it with similar limits. Although no conclusive evidence supported the value, $0.01 \mathrm{mg} / \mathrm{L}$ was adopted as an acceptable norm and applied as a WQG value (Casey, 2016). This relates to $0.01 \mathrm{mg} / \mathrm{kg}$ as the default level recommended by Regulation (EC) No 396/2005 on many residues where the maximum residue level (MRL) has not been validated.

Bromine as a non-conjugated anion $\left(\mathrm{Br}^{-}\right)$has been shown to have negative effects in mammals and poultry. $\mathrm{Br}^{-}$exerted dramatic changes on the endocrine status of rats at high doses resulting in increased thyroid mass and depressed thyroxin $\left(T_{4}\right)$ production, which caused decreased growth hormone $(\mathrm{GH})$ production and increased insulin production leading to growth retardation (Loeber et al., 1983). Acute 31-day exposure to $\mathrm{Br}^{-}$as sodium bromide $(\mathrm{NaBr})$ via feed to hatchling chicks resulted in negative effects noted by Bosshardt et al. (1956) and Doberenz et al. (1965) as stated in NRC (2005). Administered to broilers as $\mathrm{NaBr}$ at 1 and $3 \mathrm{mg} / \mathrm{L}$ in drinking water respectively, over a 42-day growth period, Br significantly decreased water and feed intakes (du Toit \& Casey, 2010). Accumulation of $\mathrm{Br}^{-}$occurred in the thyroid gland, liver and kidneys and although there was limited damage to thyroid and kidneys, explicit liver damage was reported in birds receiving higher $\mathrm{Br}^{-}$concentrations in their drinking water (du Toit \& Casey, 2012). The liver is a site of increasing concentrations of $\mathrm{Br}^{-}$accumulation with increasing treatment levels of 0.005 and $0.1 \mathrm{mg} / \mathrm{L}$ (Mamabolo et al., 2009); and 0, 1 and $3 \mathrm{mg} / \mathrm{L}$ (du Toit \& Casey, 2012). Yolk lipoprotein precursors originate in the liver, and it has been shown that drugs that deposit in the yolk are actively accumulated during the time the yolk undergoes rapid growth (Goetting et al., 2011). Albumen, which is deposited 2 - 3 hours following yolk maturation, is a possible accumulation site for drug residues (Goetting et al., 2011). The route for $\mathrm{Br}^{-}$to be present in the albumen and yolk is most likely via the liver. The strong negative correlation between embryo and albumen mass indicates albumen is a nutrient source during the critical stages of growth and development in incubation (Akil \& Zakaria, 2015). The presence of $\mathrm{Br}^{-}$in albumen and yolk would expose embryos to the risk of adverse effects.

The question is to what extent could embryos be sensitive to $\mathrm{Br}^{-}$? The hypothesis of this research was that should embryos be sensitive to $\mathrm{Br}^{-}$, a differential response occurs in the survival and development of chicken embryos following direct exposure to varying concentrations of $\mathrm{Br}^{-}$.

\section{Materials and Methods}

The project was done at the Department of Animal Nutrition and Biotechnology, Warsaw University of Life Sciences (SGGW), Poland and conformed to the requirements of EU Directive 2010/63/EU for experimental animals.

This investigation of $\mathrm{Br}^{-}$toxicity was done in three phases. For all experiments, fertilized Ross-308 broiler eggs were disinfected prior to treatment by wiping down shells with potassium permanganate $\left(\mathrm{KMnO}_{4}\right)$ solution and exposing eggs to UV light for 50 seconds. Following disinfection, the shell of each egg assigned to a treatment other than $0 \mathrm{mg} \mathrm{Br}^{-} / \mathrm{L}$ (Control), was swabbed with ethanol and a small hole made in the shell using a sterile $18 \mathrm{G}$ needle one third the distance from the narrow end of the egg. Each egg was injected into the albumen with $200 \mu \mathrm{L} \mathrm{NaBr}$ solution, the concentration of which was dependent on the assigned treatment group, using a sterile $23 \mathrm{G} \times 1 / 2$ inch needle for each egg. Excess albumen was wiped off the shell using cotton wool and the hole sealed using medical tape.

The eggs for all treatment groups were placed in the ALMD-1N3-7 incubator (FHU Walenski, Gostyn, UK) according to the method used by Sawosz et al. (2014), under the following standard conditions: Day 1 17 at $37.7{ }^{\circ} \mathrm{C}$ and humidity $60 \%$; Day $18-20$ at $37^{\circ} \mathrm{C}$ and humidity $70 \%$.

Phase 1: Five fertilized Ross-308 eggs were injected with $10 \mathrm{mg} \mathrm{Br} / \mathrm{L}\left(\operatorname{Tr}_{10 \mathrm{mg} / \mathrm{L}}\right)$. On day five of incubation, one egg was chosen at random and broken open into a clean, non-sterile petri dish for evaluation of angiogenesis with the naked eye. The embryo anatomy and the network of blood vessels were further evaluated using a Model SZX2-ILLB binocular stereomicroscope (Olympus Corporation, Japan), while attached to the yolk. The embryo was excised using a ring of filter paper and placed on a clean glass slide for a clearer field of view of its anatomy. The microscope images were recorded. On Day 10 of incubation, the remaining four eggs were broken open into individual clean, non-sterile petri dishes and evaluated with the naked eye to determine whether $\mathrm{Br}^{-}$had an effect on embryo survivability. No microscope images were taken because no live embryos were recorded.

Phase 2: 45 fertilized Ross-308 eggs were randomly assigned to three treatments (15 eggs per treatment group): $\mathrm{Tr}_{\text {omg/L }}$ (Control) $=0 \mathrm{mg} \mathrm{Br}^{-} / \mathrm{L}, \mathrm{Tr}_{5 \mathrm{mg} / \mathrm{L}}=5 \mathrm{mg} \mathrm{Br} / \mathrm{L}$, and $\operatorname{Tr}_{1 \mathrm{mg} / \mathrm{L}}=1 \mathrm{mg} \mathrm{Br} / \mathrm{L}$. After five days of incubation, samples were randomly selected from each treatment group to be examined for embryo survival as follows: $\operatorname{Tr}_{\text {omg }}$ one egg, $\operatorname{Tr}_{1 \mathrm{mg}}$ two eggs, and $\operatorname{Tr}_{5 \mathrm{mg}}$ five eggs. The eggs were broken open, their contents carefully poured into individual clean, non-sterile petri dishes and examined with the naked eye for 
signs of angiogenesis and embryo survival. No microscope images were taken at this stage. The following samples were taken on Day 18 of incubation: $\mathrm{Tr}_{0 \mathrm{mg} / \mathrm{L}} 14 \mathrm{eggs}, \mathrm{Tr}_{1 \mathrm{mg} / \mathrm{L}} 13 \mathrm{eggs}$, and $\mathrm{Tr}_{5 \mathrm{mg} / \mathrm{L}} 10 \mathrm{eggs}$, which were broken open as described and the results recorded.

Following the results of Phases 1 and 2, Phase 3 was designed such that 148 fertilized Ross-308 eggs were randomly assigned to five treatment groups: $\operatorname{Tr}_{0 \mathrm{mg} / \mathrm{L}}=0 \mathrm{mg} \mathrm{Br} / \mathrm{L}, \mathrm{Tr}_{0.01 \mathrm{mg} / \mathrm{L}}=0.01 \mathrm{mg} \mathrm{Br} / \mathrm{L}$, $\mathrm{Tr}_{0.05 \mathrm{mg} / \mathrm{L}}=0.05 \mathrm{mg} \mathrm{Br}^{-} / \mathrm{L}, \mathrm{Tr}_{0.5 \mathrm{mg} / \mathrm{L}}=0.5 \mathrm{mg} \mathrm{Br}^{-} / \mathrm{L}$, and $\mathrm{Tr}_{1 \mathrm{mg} / \mathrm{L}}=1 \mathrm{mg} \mathrm{Br} / \mathrm{L}$.

On Day 20 of incubation, eggs were randomly removed from the incubator and broken open until a minimum of six live embryos were collected per treatment group. The distribution of the total number of eggs removed $(n=59)$ differed between treatments according to the incidence of non-viable eggs occurring within a treatment group. After breaking the shell, the embryos were removed and placed in a clean, non-sterile petri dish. The number of live embryos and the macroscopic evaluation were determined according to the procedure of Hamburger \& Hamilton (1951). The embryos were allocated as live embryos when they showed signs of being alive in ovo at breakout and had died immediately post breakout. Any embryos showing signs of embryonic death before the shells were broken were recorded as dead embryos. Six live embryos per treatment were weighed and dissected to harvest the brain, heart and liver. The individual wet mass of collected organs was weighed accurately to the fourth decimal (g), and the relative organ mass was calculated against the wet mass of the whole embryo, expressed as a percentage of the total embryo mass. The remaining eggs $(n=89)$ were placed in hatching boxes in the incubator to hatch. The relative embryo survival was calculated as a percentage of live vs. dead embryos for each treatment.

Statistical analysis was done for Phase 3 only. The FREQ procedure was used to determine the chisquare goodness-of-fit test for percentages of live or dead embryos within and between treatments $(P<0.05)$ (Statistical Analyses System ${ }^{\circledR}$ ). The GLM procedure was applied to test for differences in relative organ mass between treatments by means of the F-test $(P<0.05)$. Linear correlation $\left(\mathrm{R}^{2}\right)$ relationships were established between $\mathrm{Br}^{-}$concentrations and embryo survival and mortality.

\section{Results}

Table 1 shows the results of Phases 1 and 2. The embryo from Phase $1\left(\operatorname{Tr}_{10 \mathrm{mg} / \mathrm{L}}\right)$ evaluated on Day five of incubation appeared to be viable to the naked eye, which was confirmed with subsequent microscopy. Of the remaining eggs $(n=4)$ evaluated on Day 10 of incubation, one egg was unfertilized and the remaining three showed various stages of embryonic death.

Table 1 Embryo survival between treatments $(10,5,1,0 \mathrm{mg} / \mathrm{L} \mathrm{Br})$ on selected days of incubation

\begin{tabular}{|c|c|c|c|c|c|c|c|c|c|c|c|}
\hline \multirow{2}{*}{\multicolumn{2}{|c|}{ Treatments }} & \multirow{3}{*}{ Eggs (N) } & \multicolumn{9}{|c|}{ Sampling at days of incubation } \\
\hline & & & \multicolumn{3}{|c|}{5} & \multicolumn{3}{|c|}{10} & \multicolumn{3}{|c|}{18} \\
\hline Phase & (mg/L Br) & & NF & $\mathbf{L}$ & D & NF & L & D & NF & L & D \\
\hline 1 & 10 & 5 & & 1 & & 1 & & 3 & & & \\
\hline 2 & 0 & 15 & & 1 & & & & & 3 & 11 & \\
\hline 2 & 1 & 15 & & 2 & & & & & & 2 & 11 \\
\hline 2 & 5 & 15 & 1 & 4 & & & & & & & 10 \\
\hline
\end{tabular}

NF = Not fertilized; L = Live embryo; $\mathrm{D}$ = Dead embryo

In Phase 2, randomly selected eggs from each treatment evaluated with the naked eye showed that embryos exposed to $1 \mathrm{mg} \mathrm{Br} / \mathrm{L}$ presented with varying degrees of observed angiogenesis impediment when compared with angiogenesis of the control group. Embryo mortality was observed for all eggs treated with 5 $\mathrm{mg} \mathrm{Br} / \mathrm{L}$.

On Day 18 of incubation, the eggs evaluated from $\operatorname{Tr}_{\text {omg/L }}$ showed one non-fertilized egg, and all other embryos were alive with normal development. All remaining eggs $(n=10)$ sampled from $\operatorname{Tr}_{5 \mathrm{mg} / \mathrm{L}}$ showed embryo mortality with evident proteolysis. Two live and eleven embryo deaths were observed for $\operatorname{Tr}_{1 \mathrm{mg} / \mathrm{L}}$. The live embryos showed normal development on a macroscopic scale. It was deduced from these results that $\mathrm{Br}^{-}$is lethal to embryos at concentrations $>1 \mathrm{mg} / \mathrm{L}$ and toxic at $1 \mathrm{mg} / \mathrm{L}$. 
The results of Phase 3 in Tables 2 and 3, where the chi-square determination was applied for live or dead embryos within and between treatments, show a decline in the relative number of live embryos with increasing concentrations of $\mathrm{Br}^{-}(P<0.05)$.

Table 2 Relative embryo survival (\%) within treatments

\begin{tabular}{lccc}
\hline \multirow{2}{*}{$\begin{array}{l}\text { Treatment } \\
(\mathbf{m g} / \mathbf{L ~ B r})\end{array}$} & Eggs (N) & \multicolumn{2}{c}{ \% of embryos alive / dead } \\
\cline { 3 - 4 } & & Alive & Dead \\
\hline 0 & 28 & $85.7^{\mathrm{a}}$ & $14.3^{\mathrm{b}}$ \\
0.01 & 30 & $86.7^{\mathrm{a}}$ & $13.3^{\mathrm{b}}$ \\
0.05 & 30 & $60.0^{\mathrm{a}}$ & $40.0^{\mathrm{b}}$ \\
0.5 & 30 & $43.3^{\mathrm{a}}$ & $56.7^{\mathrm{b}}$ \\
1 & 30 & $40.0^{\mathrm{a}}$ & $60.0^{\mathrm{b}}$ \\
\hline
\end{tabular}

${ }^{a, b}$ Row means with different superscripts differ significantly at $P<0.05$; F-test

Table 3 Relative embryo survival (\%) between treatments

\begin{tabular}{lccc}
\hline \multirow{2}{*}{$\begin{array}{l}\text { Treatment } \\
(\mathbf{m g} / \mathbf{L ~ B r})\end{array}$} & Eggs (N) & \multicolumn{2}{c}{ \% of embryos } \\
\cline { 3 - 4 } & & Alive & Dead \\
\hline 0 & 28 & $25.8^{\mathrm{a}}$ & $7.3^{\mathrm{b}}$ \\
0.01 & 30 & $28.0^{\mathrm{a}}$ & $7.3^{\mathrm{b}}$ \\
0.05 & 30 & $19.3^{\mathrm{a}}$ & $21.8^{\mathrm{b}}$ \\
0.5 & 30 & $14.0^{\mathrm{a}}$ & $30.9^{\mathrm{b}}$ \\
1 & 30 & $12.9^{\mathrm{a}}$ & $32.7^{\mathrm{b}}$ \\
\hline $\mathrm{a}, \mathrm{b}$ Row means with different superscripts differ significantly at $P<0.05 ;$ F-test
\end{tabular}

Table 4 shows the linear relationship between $\mathrm{Br}^{-}$concentrations and chicken embryo survival. A high negative correlation $\left(\mathrm{R}^{2}=-0.92\right)$ occurred between increasing concentrations of $\mathrm{Br}^{-}$and the percentage of embryo survival, and a high positive correlation $\left(R^{2}=0.82\right)$ occurred between increasing concentrations of $\mathrm{Br}^{-}$and the percentage of embryo mortality.

Table 4 Linear relationships between bromide $\left(\mathrm{Br}^{-}\right)$treatments $(0 \mathrm{mg} / \mathrm{L}, 0.01 \mathrm{mg} / \mathrm{L}, 0.05 \mathrm{mg} / \mathrm{L}, 0.5 \mathrm{mg} / \mathrm{L}$ and $1 \mathrm{mg} / \mathrm{L} \mathrm{Br}$ ) and chicken embryo survival (\%)

\begin{tabular}{lcccccc}
\hline & $\mathbf{R}^{\mathbf{2}}$ & Covariance & $\mathbf{r}^{\mathbf{2}}$ & $\mathbf{R t} \mathbf{M S}$ & $\mathbf{R t ~ M S E}$ & $\mathbf{P}>\mathbf{0 . 0 5}$ \\
\hline \% Embryo mortality & 0.68 & 88.43 & 0.46 & 63.73 & 12.75 & $* *$ \\
\% Hatched & -0.92 & 65.32 & 0.85 & 92.01 & 18.40 & $* *$ \\
\% Total live embryos & -0.92 & 44.16 & 0.85 & 141.08 & 28.22 & $* *$ \\
\% Total mortality & 0.82 & 73.62 & 0.68 & 70.68 & 14.14 & $*$ \\
\hline
\end{tabular}

** Significant at $P>0.05$

Table 5 shows the differences in mean relative mass for the heart, liver and brain respectively between treatment groups. Relative organ mass expressed as a percentage of the whole embryo mass $(\mathrm{g})$ was compared between treatments within each organ type, but no comparison was made between the relative masses of different organs within treatment. 
Table 5 Percentage mean $( \pm S E)$ of relative organ mass by treatment with correlation $\left(R^{2}\right)$ and slope relationships between treatments and percentage mean relative organ mass

\begin{tabular}{lccc}
\hline $\begin{array}{l}\text { Treatment } \\
\text { mg/L Br }\end{array}$ & Heart & Relative organ mass (\%) \\
\cline { 2 - 4 } & $0.8232^{\mathrm{a}} \pm 0.07$ & Liver & Brain \\
\hline 0 & $0.8588^{\mathrm{ab}^{\mathrm{b}} \pm 0.07}$ & $2.1687^{\mathrm{ab}} \pm 0.12$ & $2.3658^{\mathrm{a}} \pm 0.15$ \\
0.01 & $0.7921^{\mathrm{a}} \pm 0.07$ & $2.0048^{\mathrm{a}} \pm 0.12$ & $2.5268^{\mathrm{a}} \pm 0.15$ \\
0.05 & $1.0305^{\mathrm{b}} \pm 0.07$ & $1.8526^{\mathrm{a}} \pm 0.12$ & $2.7115^{\mathrm{ab}} \pm 0.15$ \\
0.5 & $1.0212^{\mathrm{b}} \pm 0.07$ & $2.5169^{\mathrm{b}} \pm 0.12$ & $2.6346^{\mathrm{a}} \pm 0.15$ \\
1 & 0.88 & $2.1177^{\mathrm{a}} \pm 0.12$ & $3.1456^{\mathrm{b}} \pm 0.15$ \\
$\mathrm{R}^{2}$ & 3.40 & 0.38 & 0.88 \\
Slope & & 0.67 & 1.31 \\
\hline
\end{tabular}

${ }^{a, b}$ Column means with different superscripts differ significantly at $P<0.05$; F-test

\section{Discussion}

The animal model chosen to investigate the potential toxic effects of $\mathrm{Br}^{-}$was the chicken (Gallus gallus domesticus) embryo. It has the advantages of testing the toxic effects of a substance on a whole organism level over a short period and enabling identification of a stage at which embryonic death or other effects might occur (Korhonen et al., 1982). It also enables testing of direct effects on the growing embryo independent of maternal influences present in mammalian animal models. For this reason, the method was used to study toxicological effects of various substances on the development of target organs and the whole organism, especially in current nano-medical research (Sawosz et al., 2014).

The treatments ranging from $0-1 \mathrm{mg} \mathrm{Br} / \mathrm{L}$ simulated the levels of exposure to $\mathrm{Br}^{-}$measured in groundwater throughout South Africa. Although levels as high as $18.4 \mathrm{mg} / \mathrm{L}$ have been recorded in the field, the maximum treatment concentration of $1 \mathrm{mg} / \mathrm{L}$ was set following the results of the Phases (1) and (2) (Table 1). This maximum treatment concentration was 100 times greater than the $0.01 \mathrm{mg} / \mathrm{L}$ taken to be the maximum value for a no observed adverse effect level (NOAEL) or a critical TWQR-value. The concentrations of $0,0.05$ and $0.5 \mathrm{mg} / \mathrm{L}$ on either side of $0.01 \mathrm{mg} / \mathrm{L}$ were intended to further test the sensitivity to the recommended WQG level of $0.01 \mathrm{mg} / \mathrm{L}$. The treatments were by injection into the albumen in order to have controlled treatments. In addition, the treatment method was intended to mimic the exposure to and deposition of $\mathrm{Br}^{-}$in the albumen and the yolk under controlled conditions, though direct injection into the yolk was not done. Under practical conditions, transfer to both albumen and yolk of $\mathrm{Br}^{-}$present in the blood plasma of hens exposed to $\mathrm{Br}^{-}$in drinking water may have an effect on the developing embryo similar to the negative effects ingested $\mathrm{Br}^{-}$had on the endocrine system and organs of developing broiler chickens. The concentration of $\mathrm{Br}^{-}$in the hen's plasma is a function of the concentration present in drinking water, the ingestion rate linked to the quantity of water the hen drinks and the absorption of $\mathrm{Br}^{-}$from the digestive tract into the blood plasma as reported for growing broiler chickens (Mamabolo et al., 2009; du Toit \& Casey, 2010; 2012). Since the albumen is a possible accumulation site for circulating drug residues (Goetting et al., 2011), ingested $\mathrm{Br}^{-}$could transfer a similar concentration to the albumen in a manner that mimics transplacental movement of elements from dam to foetus in mammalian species.

TWQR-values are given as a range, for example fluoride $(F)$ which has a recommended TWQR of 0 $2 \mathrm{mg} / \mathrm{L}$ for no adverse effects, 2 - $4 \mathrm{mg} / \mathrm{L}$ yielding mild adverse effects and levels $>4 \mathrm{mg} / \mathrm{L}$ causing debilitating adverse effects in livestock. Such a range has yet to be formally established for $\mathrm{Br}^{-}$. Meyer \& Casey (2012) listed particular circumstances that contribute to WQC becoming COC or PHCC. These include chronic intakes at concentrations below WQG-values if the constituents accumulate in the body, or the clearance rates are relatively low leading to an exponential accumulation until a toxicity threshold is crossed. A PHCC situation evolves under short-term or acute intakes when animals are in hypersensitive physiological stages, such as during the early growth period, and when an element is present at concentrations exceeding WQG-values. Du Toit \& Casey (2012) found $\mathrm{Br}^{-}$to be potentially toxic and an endocrine disrupting chemical (EDC) by mechanism of depressing the levels of thyroid hormones in broiler chickens, which are in the hypersensitive physiological stage of active growth.

Similarly, the high correlation coefficients shown in Table 4 indicate that chicken embryos are highly sensitive to increasing concentrations of $\mathrm{Br}^{-}$injected into the albumen. The concentrations $0.5 \mathrm{mg} / \mathrm{L}$ and $1 \mathrm{mg} / \mathrm{L} \mathrm{Br}^{-}$had the most detrimental effect on embryo survival (Tables 2 and 3). This raises the possibility of 
$\mathrm{Br}^{-}$influencing the differential development of organs and/or exerting teratogenic effects during embryo development.

The development of the three organs monitored is presented as relative organ mass against total embryo mass (Table 5). The relative organ mass was introduced to equalise mass differences that might have occurred between embryos. An increasing relative mass due to increasing treatment concentrations would indicate a differential response and hypertrophic growth. The heart showed a sequential relative organ mass response to the increasing concentrations of $\mathrm{Br}^{-}$. The mean relative mass of the heart was significantly greater for embryos treated with $0.5 \mathrm{mg} / \mathrm{L}$ and $1 \mathrm{mg} / \mathrm{L} \mathrm{Br}^{-}$respectively, compared with those from $\mathrm{Tr}_{0 \mathrm{mg} / \mathrm{L}}$ and $\operatorname{Tr}_{0.05 \mathrm{mg} / \mathrm{L}}$ with a correlation coefficient of $\mathrm{R}^{2}=0.88$ and the slope or linear rate of relative increase 3.4.

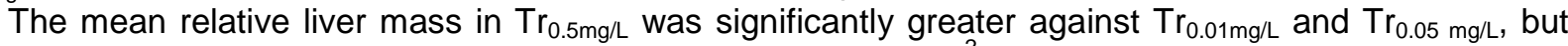
non-significantly different from $\operatorname{Tr}_{0 \mathrm{mg} / L}$. The correlation coefficient $\left(\mathrm{R}^{2}=0.38\right)$ and the low incremental rate $(<1.00)$ indicate the possibility of hypertrophic growth with increasing $\mathrm{Br}^{-}$concentrations, but this is inconclusive.

Increasing concentrations influenced the differential increase in relative brain mass significantly with the $R^{2}=0.88$ and the slope or linear rate of increase $=1.31$. The relative mean mass of the brain was significantly greater in embryos treated in $\operatorname{Tr}_{1} \mathrm{mg} / \mathrm{L}$ compared with those in $\operatorname{Tr}_{0 \mathrm{mg} / \mathrm{L}}, \mathrm{Tr}_{0.01 \mathrm{mg} / \mathrm{L}}$, and $\mathrm{Tr}_{0.5 \mathrm{mg} / \mathrm{L}}$ groups. These results show differential responses in relative mass gain with increasing concentrations of $\mathrm{Br}^{-}$ and that the heart had the greatest response and possible hypertrophic growth compared with the brain and liver. A literature search did not reveal similar research of the effect of $\mathrm{Br}^{-}$on differential organ development in chickens or other species.

It appears from the results that a level of $0.01 \mathrm{mg} / \mathrm{L} \mathrm{Br}^{-}$is sufficiently stringent as a WQG level and concurs with the conclusion of du Toit \& Casey (2012). In reality, the wide range and excessively high $\mathrm{Br}^{-}$ concentrations reported to occur naturally in groundwater indicate that many animals and humans are chronically exposed to $\mathrm{Br}^{-}$concentrations exceeding the $0.01 \mathrm{mg} / \mathrm{L}$ WQG level.

\section{Conclusions}

The results show a differential response of embryo survivability and development of the heart, liver and brain to different $\mathrm{Br}^{-}$concentrations. The concentration of $0.01 \mathrm{mg} / \mathrm{L} \mathrm{Br}$ emerged as the watershed value between concentrations that have limited or no negative effects. Concentrations $>0.01 \mathrm{mg} / \mathrm{L} \mathrm{Br}$ have potentially severe effects on developing chicken embryos, concurring with previous research on broiler chickens. In the absence of similar evidence from other livestock species, the recommendation is to accept 0 - $0.01 \mathrm{mg} / \mathrm{L} \mathrm{Br}$ as the TWQR-value.

\section{Acknowledgements}

The following persons and institutions are acknowledged: B. Strojny, Department of Animal Nutrition and Biotechnology, Warsaw University of Life Sciences, for technical support; the European Commission Erasmus+ Programme for funding student and staff exchanges between University of Pretoria, South Africa, and Warsaw University of Life Sciences, Poland. Source at https://ec.europa.eu/programmes/erasmus-plus; R.J. Coertze, Faculty of Natural and Agricultural Sciences, University of Pretoria, for assistance with statistical analyses; Water Research Commission of South Africa, Private Bag X03, GEZINA, 0031, South Africa for funding through the project WRC k5/2175. NRF for funding through the incentive grant to NHC, reference: PR-IFR180205310035/UID96806.

\section{Authors' Contributions}

The trial was a continuation of NHC's research into the effects of $\mathrm{Br}^{-}$from groundwater on livestock. The trial was designed collaboratively between the authors and executed at WULS in ES's laboratory under her guidance. The data was analysed at UP and the article developed by the three authors.

\section{Conflict of Interest Declaration}

The authors declare no conflict of interest.

\section{References}

Akil, R. \& Zakaria, A.H., 2015. Egg laying characteristics, egg mass, embryo development, hatching mass and posthatch growth in relation to oviposition time of broiler breeders. Anim. Reprod. Sci. 156, 103-110.

Bosshardt, D.K, Huff, J.W. \& Barnes, R.H., 1956. Effect of bromide on chick growth. Proc. Soc. Exp. Biol. Med. 92, 219-224.

Casey, N.H., 2016. Inorganic chemical quality of water, in Casey, N.H., Korsten, L. and Chidamba, L., 2016. Evaluation of the risks associated with the use of roof-harvested rainwater and groundwater for domestic use and livestock watering. Volume 2: Chemical quality of groundwater for potable use and livestock watering. Chapter 2: Inorganic chemical quality of water. WRC Report 2175/2/2016. ISBN 978143120875 3. Available online: www.wrc.org.za.

Casey, N.H. \& Meyer, J.A., 1996. South African Water Quality Guidelines, Second Edition. Agricultural Use: Section 4.4, Water Quality Guidelines for Livestock Watering, Volume 5. Department of Water Affairs and Forestry, 0-79885343-3. 
Casey, N.H. \& Meyer, J.A., 2001. An extension to and further refinement of water quality guideline index system for livestock watering. Volume 1: Rural communal livestock production system and wildlife production system. WRC Report No 857/1/01, Volume 1. ISBN 18684713 3; set ISBN 18684714 X. Available online: www.wrc.org.za.

Casey, N.H. \& Meyer, J.A., 2006. The application of risk assessment modelling in groundwater for humans and livestock in rural communal systems. WRC Report No 1175/1/06. ISBN: 177005467 7. Available online: www.wrc.org.za.

Doberenz, A.R., Kurnick, A.A., Hulett, B.J. \& Reid, B.L., 1965. Bromide and fluoride toxicities in the chick. Poult. Sci. 67, 32-37.

Du Toit, J. \& Casey, N.H., 2010. Effect of bromine and iodine in drinking water on production parameters of broilers. S. Afr. J. Anim. Sci. 40(4), 301-310.

Du Toit, J. \& Casey, N.H., 2012. Iodine as an alleviator of bromine toxicity in thyroid, liver and kidney of broiler chickens. Livest. Sci. 144, 269-274.

Goetting, V., Lee, A. \& Tell, L.A., 2011. Pharmacokinetics of veterinary drugs in laying hens and residues in eggs: a review of the literature. J. Vet. Pharmacol. Therap. 34(6), 521-556.

Hamburger, V. \& Hamilton, H.L., 1951. A series of normal Phases in the development of the chick embryo. J Morphol. $88,49-92$.

Korhonen, A., Hemminki, K. \& Vainio, H., 1982. Application of the chicken embryo in testing for embryotoxicity. Scand. J. Work Environ Health 8, 63-69.

Loeber, J.G., Franken, M.A.M. \& van Leeuwen, F.X.R., 1983. Effect of sodium bromide on endocrine parameters in the rat as studied by immunocytochemistry and radioimmunoassay. Fd. Chem. Toxic. 21(4), 391-404.

Mamabolo, M.C., Casey, N.H. \& Meyer, J.A., 2009. Effects of total dissolved solids on the accumulation of Br, As and Pb from drinking water in tissues of selected organs in broilers. S. Afr. J. Anim. Sci. 39(1), 169-172.

Meyer, J.A., 2015. Animal health assessment. Chapter 8. In: Investigation of the Contamination of Water Resources by Agricultural Chemicals and the Impact on Environmental Health. Volume 1: Risk Assessment of Agricultural Chemicals to Human and Animal Health. Ed. Dabrowski, J.M., WRC Report No. 1956/1/15, ISBN 978-1-43120711-4.

Meyer, J.A. \& Casey, N.H., 2012. Establishing risk assessment on water quality for livestock. Animal Frontiers 2(2), 44-49

Meyer, J.A., Casey, N.H. \& Myburgh, J., 2000. The influence of geochemistry on health risks to animals and humans in geographically localised livestock production systems. S. Afr. J. Anim. Sci. 30 (Supplement 1), 82-84.

NRC, 2005. Bromine. In: Mineral Tolerance of Animals, ( $2^{\text {nd }}$ revised ed.) pp. 72-78. ISBN 978-0-309-09654-6.

Regulation (EC) No 396/2005, of the European Parliament and of the Council of 23 February 2005 on maximum residue levels of pesticides in or on food and feed of plant and animal origin and amending Council Directive 91/414/EEC., Official Journal of the European Union.

Sawosz, E., Jaworski, S., Kutwin, M., Hotowy, A., Wierzbicki, M., Grodzik, M., Kurantowicz, N., Strojny, B., Lipińska, L. \& Chwalibog, A., 2014. Toxicity of prestine graphene in experiments in a chicken embryo model. Int. Jnl. Nanomed. 9, 3913-3922.

Statistical Analytical System $\left(\right.$ SAS $\left.^{\circledR}\right)$ 2017. SAS User's Guide: Satistics version 9.3. SAS Institute Inc. Cary, NC, USA.

World Health Organisation (WHO), 2011. Guidelines for Drinking Water Quality (4th Ed, 2011). ISBN 9789241548151. 